\title{
Sứ mệnh viết sử ngành khoa học Việt Nam: Cần những người tiếp nối
}

\author{
Phạm Hùng Hiệp
}

February 3, 2021

Kinh tế và Dư báo

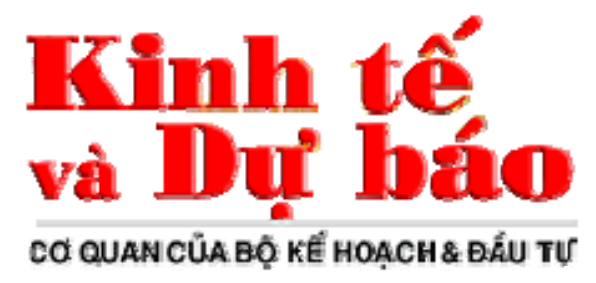

http://kinhtevadubao.vn/chi-tiet/230-18007-su-menh-viet-su-nganh-khoa-hocviet-nam--can-nhung-nguoi-tiep-noi.html 


\section{Sứ mệnh viết sử ngành khoa học Việt Nam: Cần những người tiếp nối}

Cập nhật ngày 03/02/2021 - 14:47:11

\section{f $G$ b $B$}

EFR - Một trong những người viết sử ngành mà tôi kính trọng nhất là GS. Đặng Phong, người viết sử ngành kinh tế. Tiếp nối GS. Đặng Phong, lớp hậu sinh xuất hiện nhiều học giả trẻ tuổi, nhưng người tiêu biểu tôi muốn giới thiệu là TS. Vương Quân Hoàng.

\section{Tại sao "người viết sử ngành" lại quan trọng?}

Thứ nhất, như chúng ta đều biết, Việt Nam cũng như nhiều nước đang phát triển khác đều gặp một vấn đề chung, đó là thiếu các bộ dữ liệu lớn, ở tầm mức quốc gia, giúp một người ngoài ngành có thể có được bức tranh tổng quát về một ngành/lĩnh vực/chủ điểm nghiên cứu nhất định.

Thứ hai, nhiều nhà nghiên cứu coi việc viết sử ngành là việc của nhà lịch sử chứ không phải là nhà chuyên môn trong ngành/lĩnh vực cụ thể.

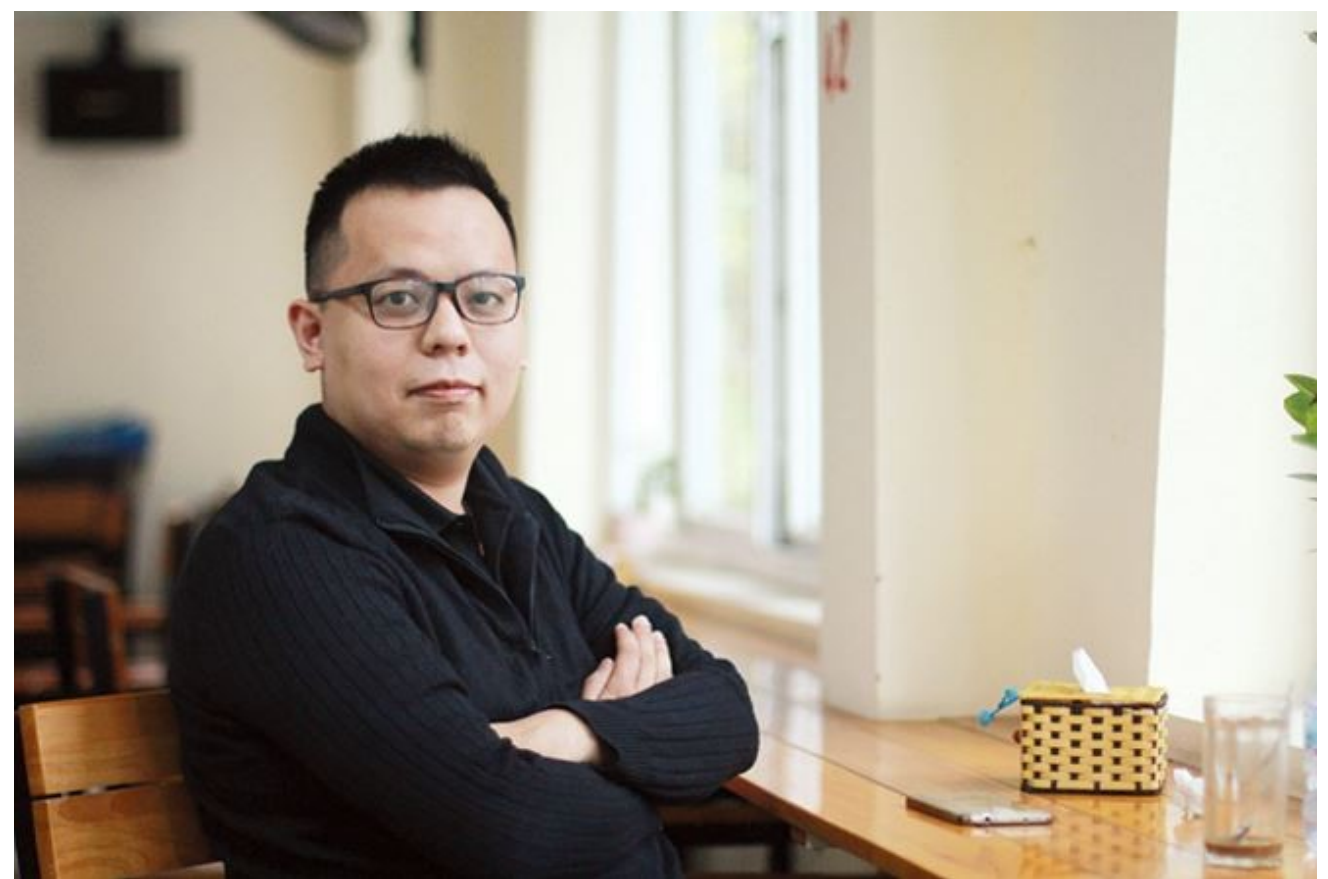

Nhũng tác phẩm hướng tới việc tổng kết một ngành/lĩnh vục/chủ điểm nhất định trong một khoảng thời gian đủ dài đóng vai trò cực kỳ quan trọng

Trong bối cảnh đó, những tác phẩm hướng tới việc tổng kết một ngành/lĩnh vực/chủ điểm nhất định trong một khoảng thời gian đủ dài, hay như tôi viết ở tiêu đề, một tác phẩm "sử ngành" đóng vai trò cực kỳ quan trọng. Tất nhiên, người có thể viết được sử ngành chắc chắn phải là người "trong ngành" đủ lâu, va vấp đủ nhiều, quan sát đủ kỹ và sắc sảo, thì tác phẩm "sử ngành" mới hay được.

Một trong những người viết sử ngành mà tôi kính trọng nhất là GS. Đặng Phong, một người viết sử ngành kinh tế. Những trước tác của ông để lại, dù là tiếng Việt, tiếng Anh hay tiếng Pháp, 
cũng đều giúp một kẻ ngoại đạo như tôi có được bức tranh toàn cảnh về vấn đề mà ông miêu tả. Đọc những tác phẩm của ông, tôi luôn có cảm giác như đang được xem một cuốn phim tài liệu về những chuyện xưa cũ, ví dụ như chuyện buôn bán ở TP. Hồ Chí Minh sau giải phóng (Đặng, 2009), hay chuyện đổi tiền ở Việt Nam những năm 1980 (Đặng, 2008). Có ý kiến còn cho rằng, không biết nên gọi Đặng Phong là sử gia viết về kinh tế hay nhà kinh tế viết sử cho ngành của mình nữa.

Tuy vậy thì các tác phẩm của Đặng Phong hơi thiếu vắng các nội dung liên quan đến giai đoạn 1990 trở đi, và đặc biệt là từ 2000 trở đi. Điều này là dễ hiểu bởi ở giai đoạn 1990-2010 (năm ông mất), Đặng Phong đã lớn tuổi, không còn xông xáo như trước nữa. Hơn nữa, cũng có thể, trong 20 năm cuối đời này (1990-2010), ông đã quá bận bịu để viết về giai đoạn những năm 1980 trở về trước, không còn thời gian đâu làm việc khác nữa?

\section{Tiếp nối sứ mệnh viết sử ngành}

Nhưng "tre già thì măng mọc", sau Đặng Phong thì lớp hậu sinh xuất hiện nhiều học giả trẻ tuổi nối bước ông. Và nếu bạn muốn tôi giới thiệu những hậu sinh tiêu biểu của Đặng Phong, thì tôi xin không ngần ngại tiến cử một người, cũng là một cộng sự "đàn anh" của tôi: TS. Vương Quân Hoàng. Không tin, các bạn hãy đọc thử các tác phẩm mà tác giả này viết chung với Phạm Minh Chính (Chính \& Hoàng, 2008, 2009) hay Bạch Ngọc Chiến (Bạch \& Vương, 2015) hay Nacy Napier (Napier \& Vuong, 2013) thì sẽ thấy.

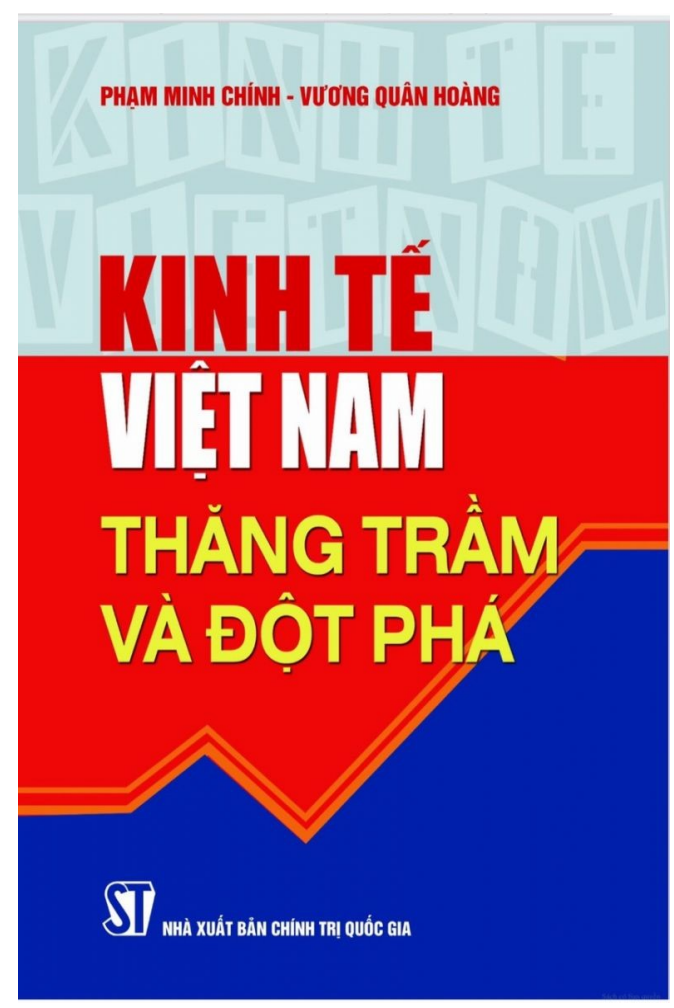

Cuốn "Kinh tế Việt Nam - Thăng trầm và đột phá" là công trình nghiên cúu một giai đoạn phát triển sôi động bậc nhất của nền kinh tế Việt Nam thời kỳ đổi mới

Đặc biệt, cuốn "Kinh tế Việt Nam - Thăng trầm và đột phá” được Nhà xuất bản Chính trị Quốc gia - Hà Nội xuất bản lần đầu vào tháng 5 năm 2009. Tác phẩm này là một công trình nghiên cứu khoa học của hai tác giả Phạm Minh Chính và Vương Quân Hoàng về kinh tế Việt Nam trong thời kỳ khủng hoảng kinh tế và hội nhập và là công trình nghiên cứu một giai đoạn phát triển sôi động bậc nhất của nền kinh tế Việt Nam thời kỳ đổi mới. Tác phẩm viết về nền kinh tế của Việt Nam với trọng tâm nghiên cứu đặt vào hệ thống tài chính - tín dụng - tiền tệ, mô tả toàn cảnh nền kinh tế Việt Nam với mong muốn để lại trong độc giả những suy nghĩ về hành trình tiếp tục chinh 
phục nền kinh tế toàn cầu, cùng giấc mơ nước Việt Nam phát triển và thịnh vượng.

Từ góc độ cá nhân, tôi cũng rất muốn mình trở thành một người viết sử của ngành mình (giáo dục). Tất nhiên, trong thời điểm hiện tại, tôi chưa đủ sức đề viết những tác phẩm dài hơi, dày dặn như của Đặng Phong hay Vương Quân Hoàng, Phạm Minh Chính, Bạch Ngọc Chiến. Mặc dù vậy, trong điều kiện có thể, tôi và các cộng sự cũng đã cố gắng công bố một số tác phẩm ngắn, mang hơi hướng “chép sử”, ví dụ xem (T-T. Nguyen và cộng sự, 2020 hoặc T. T. H. Nguyen và cộng sự, 2020).

Về lâu dài, tôi rất muốn viết một cuốn sách, viết lại lịch sử quá trình "xã hội hóa giáo dục" (hay chính xác hơn là "thương mại hóa giáo dục") (xem Phạm \& Vũ, 2019) tại Việt Nam, mà có lẽ được khởi động đầu tiên với việc Trung tâm Đại học Thăng Long (tiền thân của Đại học Thăng Long ngày nay) ra đời vào năm 1988.

Nhân dịp này, tôi cũng muốn kêu gọi các đồng nghiệp, dù là ngành khoa học tự nhiên hay xã hội nhân văn hãy quan tâm hơn đến chủ đề "viết sử” này.

Lời cảm ơn: Tác giả xin chân thành cảm ơn hai cộng sụ Đoàn Phuoong Thục và Đỗ Hải Hoàng Nam đã hố trọ̣ khi viết bài này.

\section{TÀI LIỆU THAM KHẢO}

Bạch, N. C. \& Vương, Q. H. (2015). Bằng chứng cuộc sống: Suy ngẫm về phát triển bền vững Việt Nam . Nhà xuất bản Chính trị Quốc gia.

Chính, P. M., \& Hoàng, V. Q. (2008). Bối cảnh tài chính Việt Nam 1997-1998 và 2007-2008:

Khoảng cách và biến đối. Nghiên cứu Kinh tế, 48(7), 3-24.

Chính, P. M., \& Hoàng, V. Q. (2009). Kinh tế Việt Nam: Thăng trầm và đột phá. Nxb Chính trị Quốc gia, Hà Nội.

Đặng, P. (2008). Tư duy kinh tế Việt Nam - Chặng đường gian nan và ngoạn mục 1975 - 1989. Nhà xuất bản Tri thức.

Đặng, P. (2009). "Phá rào" trong kinh tế vào đêm trước Đổi mới. Nhà xuất bản Tri thức.

Napier, N. K. \& Vuong, Q. H. (2013). What we see, why we worry, why we hope: Vietnam going forward. Boise State University CCI Press.

Nguyen, T-T., Trinh, T. P. T., Ngo, H. T. V., Hoang, N-A., Tran, T., Pham, H-H., \& Bui, V-N. (2020). Realistic Mathematics Education in Vietnam: recent policies and practices. International Journal of Education and Practice, 8(1), pp. 57-71. https://doi.org/10.18488 Ljournal.61.2020.81.57.71

Nguyen, T. T. H., Pham H-H., Vuong, Q-H., Cao, Q-T., Dinh, V-H., Nguyen, D. D. (2020). The adoption of international publishing within Vietnamese academia from 1986 to 2020: a review. Learned Publishing. https://doi.org/10.1002/leap.1340

Pham, H. H., \& Vu, H. M. (2019). Financing Vietnamese Higher Education: From a Wholly Government-Subsidized to a Cost-Sharing Mechanism. In Reforming Vietnamese Higher Education (pp. 75-90). Springer, Singapore.

Phạm Hùng Hiệp, Giám đốc Trung tâm Nghiên cứu và thực hành giáo dục, Trường đại học Phú Xuân, Huế 